\title{
IS FLEXIBLE CYSTOSCOPY NECESSARY IN THE INVESTIGATION OF NON- VISIBLE HAEMATURIA?
}

Jennifer Nowers ${ }^{1}$, Mark O. Kitchen ${ }^{1} 2^{\star}$, Sneha Rathod ${ }^{1}$, Caroline Lipski ${ }^{1}$, Sharbathana Nageswaran ${ }^{1}$, Shahjahan Aslam ${ }^{1}$, Anurag Golash ${ }^{1}$

${ }^{1}$ Urology Department, University Hospitals of North Midlands NHS Trust, Staffordshire, UK; ${ }^{2}$ School of Medicine, Keele University, Staffordshire, UK

\section{*Author for correspondence: Mark O. Kitchen: m.o.kitchen@keele.ac.uk.}

\begin{abstract}
Background: Historic evidence suggests up to 16\% (approximately) of non-visible haematuria (NVH) referrals result in Urological cancer diagnosis. The majority are bladder cancers, for which flexible cystoscopy is regarded the "gold standard" diagnostic procedure. Recent changes to suspected cancer referral guidelines, public information campaigns and reduced smoking prevalence may have changed this percentage. We retrospectively calculated cancer detection rates from NVH referrals to assess whether flexible cystoscopy, an invasive and morbid procedure, remains necessary.

Patients and methods: All patients referred to our University teaching hospital on a suspected ("twoweek") cancer pathway with NVH over a 16-week period were included. Clinical and demographic data were collected for a series of 200 patients (96 male, age range 27-92, median 68).

Results: Only eight patients had urological malignancy found (two renal and six bladder cancers). Both renal, and four bladder cancers, were identified on imaging prior to flexible cystoscopy. Only two bladder cancers were therefore detected by cystoscopy; one low-risk non-muscle invasive (patient has already been discharged) and one in a patient that was unfit for treatment (died of heart failure). Only seven (3.5\%) of the patients were offered the option of not undergoing flexible cystoscopy.

Conclusion: Our analyses suggest that flexible cystoscopy is rarely of benefit in patients with NVH. We suggest that patients should be given an accurate risk of bladder cancer diagnosis during the consent process. We advocate that flexible cystoscopy can be avoided for the majority of NVH referrals, particularly in patients without strong risk factors for urothelial cell carcinoma. Avoidance of flexible cystoscopy would reduce patient risks from procedural morbidity, reduce risks of acquiring coronavirus from hospital attendance, and there could be huge reductions in financial and service delivery demands in an overstretched secondary-care service.
\end{abstract}

\section{INTRODUCTION}

Flexible cystoscopy (FC) has been considered the "gold standard" to visualize the bladder for several decades. ${ }^{1}$ As such, it is recommended in the investigation of haematuria by the National Institute for Health and Care Excellence (NICE) and European Association of Urology (EAU) Bladder Cancer guidelines. ${ }^{2,3}$ However, despite improvements in technology and vision/resolution, FC remains a user-dependent procedure, with poor sensitivity for flat urothelial lesions such as carcinomain-situ (CIS). ${ }^{4}$ Therefore, it comprises only part of a multi-modal approach to haematuria investigation.

FC can be a morbid procedure, causing considerable (but temporary) irritative lower urinary tract symptoms 
for a significant number of patients. ${ }^{5}$ It also has attributable risks of infection (up to $10 \%$ ) and sepsis $(<1 \%)$, particularly in immunocompromised patients or those with long-term catheters. ${ }^{6}$ Furthermore, many patients find FC an undignified and intrusive procedure, and it is occasionally so poorly tolerated that general anaesthetic is required, also with potential inherent patient morbidity. ${ }^{5}$

Despite these risks and limitations, (largely historic) evidence regarding the prevalence of urological malignancy in patients with non-visible haematuria (NVH), up to $16.1 \%$, perpetuates the perceived need for its use. ${ }^{4}$ However, population smoking prevalence is falling, suspected cancer referral pathways and definitions of haematuria have altered, and environmental risks, particularly occupational exposures, have been recognised and mitigated. These factors are likely to have reduced the true prevalence of urological malignancy in patients with $\mathrm{NVH}$; relating this to patients as a percentage risk of identifying bladder cancer prior to FC should be considered an integral part of informed consent.

Perhaps the most important current concern is the need to ensure patient safety during the coronavirus pandemic. A significant number of coronavirus cases (up to $15 \%$ ) are thought to be acquired within hospitals. ${ }^{7}$ Therefore, by reducing hospital attendances, for instance FC clinic, risks to patients from coronavirus may be decreased. Furthermore, one must also consider the service and economic burden of performing FC (including staff, theatre, and equipment costs), again, particularly during the Coronavirus pandemic where health and social care services are significantly financially over-stretched.

The considered parameter was if the benefits of FC justified its continued use in the diagnosis of patients with NVH on the suspected cancer pathway, by evaluating the diagnostic yield in the NVH population in relation to the need to protect patients during the coronavirus pandemic, the procedural morbidity and mortality, and service provision and financial demands.

\section{PATIENTS AND METHODS}

A consecutive case series of 200 patients, referred from primary care on a suspected urological cancer pathway for investigation of $\mathrm{NVH}$, was identified at our tertiary cancer centre and University teaching hospital. All patients fulfilled NICE criteria for the suspected cancer referral, and therefore were referred after treatment of UTI if this was initially present. $^{2}$

All patients who attended were assessed by "twostop" clinic, comprising (first-stop) nurse-led history and investigations and (second-stop) urologist review, discussion of investigation results, and flexible cystoscopy as indicated. Smoking status, family history and occupational risk factors for urothelial cell carcinoma (UCC) were recorded for each case.

As recommended by NICE guidelines, investigations comprised: blood tests (including renal function, and prostate-specific antigen in men), urine tests including protein: creatinine ratio, microbiological culture and cytology (UC) (as urinary biomarker), and renal tract ultrasound.

Microsoft Excel (Microsoft Corporation, USA, v16.0, 2016) and online Social Science Statistics software $^{8}$ were used for data and statistical analyses. Multivariate regression was used to identify potential risk groups for requiring or not requiring flexible cystoscopy $(\mathrm{P}<0.05$ considered significant $)$; otherwise simple descriptive methods were used.

\section{RESULTS}

\section{Demographics}

A total of 104 female and 96 male patients were included, age range 27-92 (median 68); 21 were current smokers, 48 were ex-smokers, 18 had occupational risk factors, and three had relevant family history for UCC (Table 1).

\section{Urological malignancy found (renal, prostate, bladder)}

Eight urological malignancies were identified from our NVH population (two renal tumours and six bladder tumours) (Figure 1).

Six out of eight cancers were identified on imaging prior to FC: both renal tumours and six bladder tumours were detected by renal tract ultrasound (US) or computed tomography urogram (CTU).

None of the bladder cancers were indicated by abnormal urine cytology. 
Table 1. Patient Demographics

\begin{tabular}{|l|c|c|c|c|c|c|c|}
\hline & $\begin{array}{c}\text { Total } \\
\text { number }\end{array}$ & $\begin{array}{c}\text { Age } \\
\text { range }\end{array}$ & $\begin{array}{c}\text { Median } \\
\text { age }\end{array}$ & $\begin{array}{c}\text { Current } \\
\text { smokers }\end{array}$ & Ex-smokers & $\begin{array}{c}\text { Occupational risk } \\
\text { factors }\end{array}$ & $\begin{array}{c}\text { Family } \\
\text { history }\end{array}$ \\
\hline Male & 96 & $27-92$ & 67 & 10 & 28 & 11 & 1 \\
\hline Female & 104 & $31-88$ & 68 & 11 & 20 & 7 & 2 \\
\hline
\end{tabular}
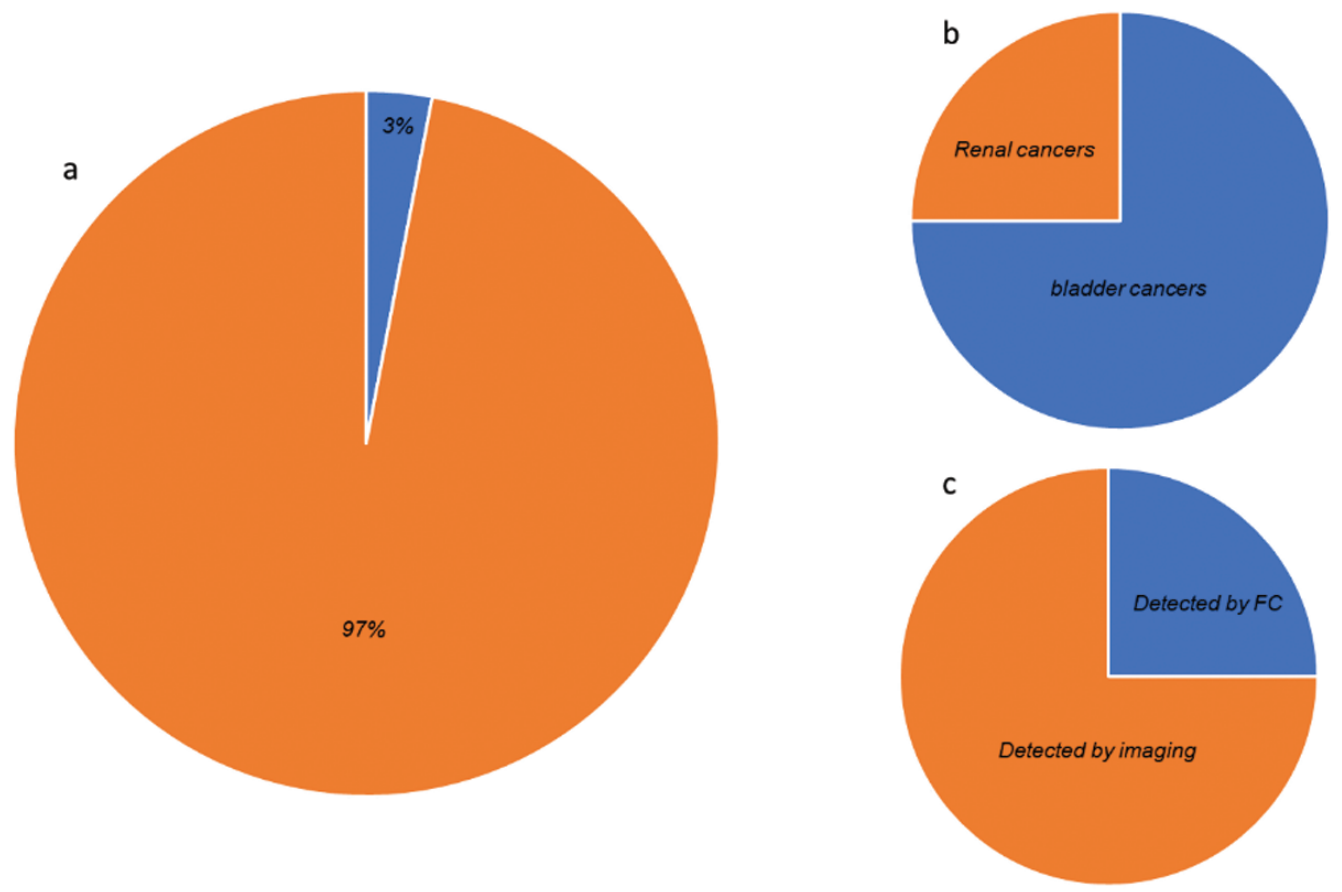

Figure 1. Cancers found. (a) Pie-chart representation of the number of bladder cancers found in our NVH case series: the orange segment represents no cancer found $(\mathrm{n}=194,97 \%)$ and the blue segment represents bladder cancers found $(n=6,3 \%)$. (b) Pie-chart representation of all cancers found by site: the blue segment represents bladder cancers $(n=6)$ and the orange segment represents renal cancers $(n=2)$. (c) Pie-chart representation of cancers identified by imaging prior to FC (bladder cancers orange segment, $\mathrm{n}=6$, and renal cancers blue segment, $\mathrm{n}=2$ ).

No prostate cancers were suggested by screening PSA and/or DRE (that were subsequently proven on mpMRI and/or prostate biopsy).

Two bladder tumours were identified only by FC: in these cases, one was a sub-centimetre solitary G1pTa (patient already discharged from follow-up), and the other was a solitary $2 \mathrm{~cm}$ pedunculated papillary tumour, however, the patient was unfit for trans-urethral resection and has since died of heart failure.

\section{Regression analyses}

Multivariate regression analyses did not find any significant correlation with age, gender, smoking status, or occupational or family risk factors to bladder cancer diagnosis.

\section{DISCUSSION}

There are multiple conflicting factors regarding the need for $\mathrm{FC}$ in $\mathrm{NVH}$ patients. The risk of bladder 
cancer missed by preliminary investigations and patient choice (FC may be wanted for "peace of mind"), compete with user-dependence, poor sensitivity, associated morbidity, the large number of FC needed to identify each bladder cancer and demands on service provision. Moreover, the current coronavirus pandemic and government guidance to reduce travel and patient hospital attendances (even for outpatient procedures), must also be taken into consideration.

Despite high smoking rates locally (18.9\% compared to national average $14.4 \%{ }^{9}$ ), and multiple occupational risk factors for bladder UCC within our catchment area, particularly tyre manufacture and the pottery industries, we identified bladder cancer in only $3.0 \%$ of our NVH patients. This is similar to the weighted average in a recent review ${ }^{4}$ and is reassuring that despite the presence of strong UCC risk factors in our series, the prevalence of bladder cancer in patients with $\mathrm{NVH}$ is much lower than historically reported.

Though the low prevalence of bladder cancer in our series precluded meaningful regression analyses that might identify specific risk factors, four of six patients in whom bladder cancer was found were smokers or ex-smokers, and four were over 70. Previous reports also suggest that older (male) smokers have the highest rates of bladder cancer in patients with $\mathrm{NVH}$, and advocate targeting this "high-risk" population for full investigation including FC. ${ }^{10}$

Encouragingly in our series, similar to previous studies ${ }^{4}$ FC appears to have a low diagnostic yield in NVH patients, and most tumours were identified by renal tract US. Indeed, 100 flexible cystoscopies needed to be performed to identify one bladder cancer. One must be mindful of the limitations of renal tract US in that it may not identify all bladder cancers, particularly where patients cannot fill their bladder, and with small and carpet-like papillary tumours, and CIS. However, small papillary tumours are typically low-risk and are unlikely to lead to patient harm if not found immediately, and CIS most commonly presents with concurrent UCC, is more likely to be detected by urinary biomarker(s), and can often be missed during FC anyway. ${ }^{11}$ Notwithstanding, patients with occupational or environmental risk factors for UCC should undergo CT Urogram rather than US. ${ }^{4}$
Reassuringly, if a cancer is missed initially by US, the patient is likely to represent with further episodes of $\mathrm{NVH}$, or with new $\mathrm{VH}$, but the very low rate $(<1 \%)$ of re-presentation (with bladder cancer) up to 14 years after initial referral, suggests that very few tumours are missed (particularly clinically significant ones) and supports that avoidance of FC in patients with NVH is safe. ${ }^{4}$

Although procedural morbidity can be significant, ${ }^{5,6,12}$ none of our patients re-presented acutely to the Trust within 30 days of FC. It was not possible to ascertain the number of patients with urinary tract symptoms, or those presenting to primary care services with urinary tract infection, as these data are not routinely recorded and our approach was retrospective. Notwithstanding, the number of patients previously reported suffering symptoms, infection, and sepsis following FC dwarfs the prevalence of bladder cancer that was identified.

Considering that most patients referred for investigation of NVH in our series are elderly and comorbid, they are at increased risk of acquiring coronavirus, at significantly increased risk of adverse outcomes from coronavirus infection. ${ }^{13}$ Worryingly, up to $15 \%$ of coronavirus cases are thought to be transmitted or "caught" in hospital settings, ${ }^{7}$ although we were unable to assess the number of coronavirus cases in our patients that may have been related to their FC appointment. Nevertheless, patient attendance for FC should be considered an avoidable risk factor for coronavirus infection and reason enough on its own to avoid routine $\mathrm{FC}$ to $\mathrm{NVH}$ patients.

Whilst consent processes for FC differ throughout the UK, ${ }^{14}$ from simple implied (patient attends for the procedure) to two stage full written consent using patient information leaflets (prior to FC appointment and at time of FC), counselling patients of risks, benefits and alternatives should be undertaken as best practice. However, despite the low prevalence of bladder cancer in the study patients with $\mathrm{NVH}$, only $4.5 \%$ of patients were offered the option of not proceeding to $\mathrm{FC}$; although many of our patients may be deemed high risk, it is clear that our pre-procedure patient counselling process is inadequate. Indeed, even if $\mathrm{FC}$ remains in routine use for NVH patients (where, for example, benign causes have been excluded ${ }^{4}$ ), it is possible that 
clear discussion of the low risks of finding bladder cancer would prompt patients to decline FC on a risk versus benefit judgment, despite many patients being initially keen for referral and investigation. ${ }^{4}$

Although patient safety and decreasing unnecessary invasive investigations and risks are the key drivers to our study, there are potentially huge reductions in financial outlay and service demands that could be made, if FC were not routinely performed for $\mathrm{NVH}$ patients. For example, our Trust could save more than $750(\mathrm{NVH})$ patient appointments and an estimated $£ 220,000$ per year, potentially reducing waiting list times for visible haematuria and other urgent referrals, and freeing funds for other essential services.

\section{CONCLUSION}

Although it is difficult to prove from our series, the risks and associated procedural morbidity of FC almost certainly outweigh the potential benefits in patients with $\mathrm{NVH}$, given the low prevalence of bladder cancer and the minimal risk of missing clinically significant disease. The demand on over-stretched resources, and the need to reduce unnecessary hospital attendance during the global coronavirus pandemic, are also strong arguments that we should not routinely perform $\mathrm{FC}$ for patients with NVH. The authors advocate, however, the use of clinical judgement in all cases and suggest the risk versus the benefit is discussed with patients to inform their decision-making.

\section{FUNDING}

N/A

\section{CONFLICTS OF INTEREST}

All authors declare no conflicts of interest.

\section{ACKNOWLEDGEMENTS}

N/A

\section{AUTHORSHIP CREDIT}

Concept and design of study: MK, AG

Acquisition of data, or analysis and interpretation of data: MK, SR, CL, SN, AA

Drafting the article or revising it critically for intellectual content: JN, MK
Final approval of the version to be published: JN, MK, AG

\section{REFERENCES}

1. Samplaski MK, Jones JS. Two centuries of cystoscopy: The development of imaging, instrumentation and synergistic technologies. BJU Int. 203;103(2):154-8. http://dx.doi.org/10.1111/j.1464-410X.2008.08244.x

2. Bladder cancer: Diagnosis and management NICE guideline [NG2] [Internet]. 2015 [cited $2021 \mathrm{Feb} 04$ ]. Available from: https://www.nice.org.uk/guidance/ ng2/chapter/1-Recommendations\#diagnosing-andstaging-bladder-cancer-2

3. Babjuk M, Burger $\mathrm{M}$, Compérat $\mathrm{E}$, Gontero $\mathrm{P}$, Liedberg F, Masson-Lecomte A, et al. European Association of Urology (EAU) guidelines non-muscle invasive bladder cancer [Internet]. 2021 [cited 2021 Feb 04]. Available from: https://uroweb.org/guideline/ non-muscle-invasive-bladder-cancer/

4. Jubber I, Shariat SF, Conroy S, Tan WS, Gordon PC, Lotan Y, et al. Non-visible haematuria for the detection of bladder, upper tract, and kidney cancer: An updated systematic review and meta-analysis. Eur Urol. 2020;77(5):583-98. http://dx.doi.org/10.1016/j. eururo.2019.10.010

5. Burke DM, Shackley DC, O'Reilly PH. The community-based morbidity of flexible cystoscopy. BJU Int. 2002 Mar;89(4):347-9. http://dx.doi. org/10.1046/j.1464-4096.2001.01899.x

6. Cusumano JA, Hermenau M, Gaitanis M, Travis M, LaPlante KL, Tran TY, et al. Evaluation of post-flexible cystoscopy urinary tract infection rates. Am J Health Syst Pharm. 2020;77(22):1852-8. http://dx.doi. org/10.1093/ajhp/zxaa270

7. National health Service (NHS) England. COVID-19 hospital activity [Internet]. [cited $2021 \mathrm{Feb} 06$ ]. Available from: https://www.england.nhs.uk/statistics/ statistical-work-areas/covid-19-hospital-activity/

8. Social Science Statistics online software [Internet]. [cited 2021 Mar 19]. Available from: https://www. socscistatistics.com/

9. Stoke-On-Trent tobacco control strategy $2015 / 18$ [Internet]. [cited $2021 \mathrm{Feb} 13$ ]. Available from: www. stoke.gov.uk/download/downloads/id/788/tobaccocontrol-strategypdf.pdf

10. Tan WS, Feber A, Sarpong R, Khetrapal P, Rodney S, Jalil R, et al. Who should be investigated for haematuria?

J Endolum Endourol Vol 4(2):e7-e12; June 22, 2021.

This article is distributed under the terms of the Creative Commons AttributionNon Commercial 4.0 International License. (c) Nowers, et al. 
Results of a contemporary prospective observational study of 3556 patients. Eur Urol. 2018 Jul;74(1):10-14. http://dx.doi.org/10.1016/j.eururo.2018.03.008

11. Casey RG, Catto JWF, Cheng L, Cookson MS, Herr $\mathrm{H}$, Shariat $\mathrm{S}$, et al. Diagnosis and management of urothelial carcinoma in situ of the lower urinary tract: A systematic review. Eur Urol. 2015;67(5):876-88. http://dx.doi.org/10.1016/j.eururo.2014.10.040

12. Clennon EK, Acevedo AM, Sajadi KP. Safety and effectiveness of zero antimicrobial prophylaxis protocol for outpatient cystourethroscopy. BJU Int. 2019 May;123(5A):E29-33. http://dx.doi.org/10.1111/bju.14662

13. Rod JE, Oviedo-Trespalacios O, Cortes-Ramirez J. A brief-review of the risk factors for covid-19 severity. Rev Saude Publica. 2020;54:60. http://dx.doi. org/10.11606/s1518-8787.2020054002481

14. Hrouda D, Emberton M, Hampson SJ. Written consent is haphazard for minor urological procedures. Br J Urol. 1997 Apr;79(4):503-4. http://dx.doi. org/10.1046/j.1464-410x.1997.00104.x

J Endolum Endourol Vol 4(2):e7-e12; June 22, 2021.

This article is distributed under the terms of the Creative Commons Attribution-

Non Commercial 4.0 International License. (c) Nowers, et al. 